\title{
PERFIL E PRÁTICAS SEXUAIS DE UNIVERSITÁRIOS DA ÁREA DE SAÚDE
}

\author{
Profile and Sexual Practical of \\ College Students from Health Area \\ Perfil y Prácticas Sexuales de \\ Universitarios del Área de Salud
}

José Stênio Pinto Falcão Júnior

Lydia Vieira Freitas
Samia Thábida de Oliveira Rabelo

Ana Karina Bezerra Pinheiro
Emeline Moura Lopes

Lorena Barbosa Ximenes

\section{Resumo}

0 estudo teve como finalidade descrever o perfil sexual de acadêmicos da área da saúde da Universidade Federal do Ceará e investigar o conhecimento dos mesmos acerca das condutas e práticas voltadas para a contracepção e prevenção das doenças sexualmente transmissíveis (DST). Os dados foram obtidos através da aplicação de um questionário composto de 16 questões objetivas, abordando dados biográficos e relacionados à educação sexual, práticas sexuais, aquisição de DST e gravidez não planejada. Os resultados encontrados mostram que não há uma associação direta entre o nível de escolaridade e o nível de conhecimento e a utilização dos métodos que previnem as DST/AIDS e gravidez indesejada.

Palavras-chave: Sexualidade. Doenças Sexualmente Transmissíveis. Gravidez não Desejada. Comportamento Sexual.

\begin{abstract}
The study had as purpose to describe the sexual profile of academics of the health area of the Federal University of Ceará and to investigate their knowledge about the behavior and practices directed to the contraception and prevention of the sexual transmission disease (STD). The data was collected through the application of a composed questionnaire with 16 objective questions, approaching biographical data and related them to the sexual education, sexual practice, acquisition of STD and no planned pregnancy. The found results didn't showed that there isn't a direct association between the level of knowledge and the use of the methods to prevent STDs and AIDS besides not desired pregnancy.
\end{abstract}

\section{Resumen}

El estudio tuvo como finalidad describir el perfil sexual de académicos del área de salud de la Universidad Federal del Ceará e investigar el conocimiento de los mismos acerca de las conductas y prácticas relacionadas a la contracepción y prevención de las Enfermedades Sexualmente Transmisibles (ETS). Los datos fueron obtenidos a través de la aplicación de un cuestionario compuesto de 16 preguntas objetivas, abordando datos biográficos y relacionados a la educación sexual, prácticas sexuales, adquisición de ETS y embarazo no planeado. LoS resultados encontrados muestran que no hay una asociación directa entre el nivel de escolaridad y el nivel de conocimiento y la utilización de los métodos que previenen las ETS/SIDA y el embarazo indeseado.
Keywords: Sexuality. Sexually Transmitted Diseases. Pregnancy Unwanted. Sexual Behavior.
Palabras clave: Sexualidad. Enfermedades Sexualmente Transmisibles. Embarazo no Deseado. Conducta Sexual. 


\section{INTRODUÇÃO}

A sexualidade é vista como um conjunto de expressões ou comportamentos do ser humano, de modo a influenciar todo o ciclo de vida, por estar relacionada a fatores biológicos, psicológicos e sociais, dentre estes a procriação e a autoafirmação social e individual'.

De acordo com Souza e Osório, a sexualidade faz parte da vida e o seu equilíbrio depende da estabilidade emocional do indivíduo. Entre os seres humanos, a sexualidade não diz respeito apenas às funções de reprodução; ela inclui necessariamente 0 amor e o prazer ${ }^{2}$.

A sexualidade humana também é entendida como uma construção histórica e cultural com base nas experiências vivenciadas pelos indivíduos em seus vários ambientes de inserção ${ }^{3}$. Esta quando tratada como fator isolado a outros aspectos sócio-culturais é utópica, por ser um processo ininterrupto, acompanhando o indivíduo por todo o seu ciclo de vida, recebendo diversas influências, sendo estas fisiológicas, emocionais, culturais ${ }^{4}$.

A sexualidade humana é um assunto inerente a todos os seres humanos e de suma importância, porém esta acarreta uma série de tabus no que diz respeito à sua discussão. Mesmo com o amplo avanço científico e tecnológico ocorrido nas últimas décadas, a sexualidade humana continua sendo considerada um tema repleto de mitos e preconceitos ${ }^{4}$.

A concepção sobre a sexualidade humana tem evoluído historicamente. 0 século XVII marcou a história da sexualidade porque criou um conjunto de pudores que valorizava a decência e condenava o sexo pré-nupcial. As opiniões e as regras da época começaram a ser questionadas até que, no século XX, esses questionamentos chegaram a romper com as proibições da sociedade, eliminando muitos tabus relacionados à sexualidade humana, diminuindo o constrangimento e a recriminação ${ }^{5}$.

Assim, as relações sexuais tornaram-se menos comprometedoras e a sexualidade feminina não inteiramente ligada à procriação, caracterizando $a$ isenção às responsabilidades futuras, bem como um maior enfoque a conduzida pela busca do prazer ${ }^{6}$.

Dessa forma, muitos jovens, em face da nova concepção liberal, passaram a iniciar a prática sexual de maneira desordenada, não se prevenindo contra as doenças sexualmente transmissiveis (DST) e de uma gravidez indesejada.

A consciência de que algumas precauções são necessárias para se realizarem certas prática sexuais pode depender do nível sócio-econômico, de escolaridade e da idade. A taxa de fecundidade tende a ser maior entre adolescentes e jovens que apresentam menor escolaridade e que não possuem nenhuma atividade remunerada, e o uso de contraceptivos é menor quanto menor a idade do adolescente. Porém, é real o fato de que o uso de métodos contraceptivos não está necessariamente associado ao conhecimento. Um menor índice de uso de métodos anticoncepcionais não está relacionado diretamente com a falta de informação ${ }^{7}$.

A adolescência é um estágio da vida em que a pessoa passa por profundas transformações e vivencia novas experiências no que diz respeito à sexualidade, porém, muitas pessoas não estão preparadas para a iniciação sexual e submetem-se aos riscos ou até mesmo às frustrações. A idade da primeira relação sexual está entre 15 anos para os homens e 17 anos para as mulheres; dentre estes, apenas $51,4 \%$ fizeram o uso de métodos contraceptivos ${ }^{8}$. A atividade sexual tem se iniciado cada vez mais precocemente e é mantida de forma freqüente entre adolescentes ${ }^{9}$.

Assim, a população jovem é considerada um grupo de relevância nas práticas de ações preventivas e em pesquisas acerca do tema DST/AIDS, isto por conta da alta exposição aos fatores e atividades que predispõem à contaminação.

No Brasil, do total de 13.844 casos de AIDS diagnosticados em 2004, 1.085 casos (28,22\%) são de jovens com idade de 13 a 24 anos $^{3}$. Já quanto ao risco para aquisição de outras DST's, indivíduos na faixa etária de 15 a 24 anos de ambos os sexos são os que apresentam as mais altas taxas de infecção na maioria dos países ${ }^{10}$.

Certas práticas sexuais provocam uma maior exposição do jovem às doenças e/ou à gravidez não planejada, deixando-o em risco quanto a sua saúde. 0 não-uso do preservativo e de métodos contraceptivos estão incluídos entre os fatores que são considerados ao analisarmos as práticas de risco. Ao negligenciarem a prática da contracepção e de prevenção às doenças sexualmente transmissíveis, adolescentes e jovens podem se expor ao HIV/ AIDS e às demais doenças sexualmente transmissíveis, bem como à gravidez não planejada, revelandose esta realidade como potencialmente imediata ${ }^{10}$.

Apesar de no meio acadêmico haver maior acesso às informações acerca da sexualidade humana e aos fatores de exposição às possíveis conseqüências de práticas sexuais inseguras, torna-se relevante o estudo do perfil sexual da população universitária, por estar a mesma em um período de transição em sua vida, no que diz respeito aos comportamentos social e sexual.

Assim, surgiu o interesse em investigar as condutas e práticas voltadas para a contracepção e prevenção das doenças sexualmente transmissíveis na população de acadêmicos da Faculdade de Farmácia, Odontologia e Enfermagem da Universidade Federal do Ceará.

\section{METODOLOGIA}

Estudo de corte transversal realizado através de um inquérito. Pesquisa com desenho exploratório, em que interessa descrever e categorizar fenômenos em um grupo de pessoas. Utilizou-se abordagem quantitativa que se fundamenta no ser humano como um complexo de muitos sistemas que podem ser medidos objetivamente, de forma separada ou combinada, onde a pesquisa mede uma ou mais características humanas, controlando variáveis enfocadas no estudo ${ }^{11}$.

A população foi composta pelos acadêmicos da Faculdade de Farmácia, Odontologia e Enfermagem (FFOE), da Universidade Federal do Ceará, durante os meses de maio e junho 2005. Foram escolhidos os alunos destes cursos por serem pertinentes à área da saúde, ou seja, um grupo que deveria possuir conhecimentos sobre o assunto e manter hábitos de vida saudável, estando aptos a expandir informações inerentes à sexualidade humana. Foi considerado ainda o fato 
de que estes cursos pertencem ao mesmo centro da Universidade e se localizam na mesma área geográfica.

A amostra foi composta por 303 alunos, sendo 129 alunos do curso de Farmácia, 78 alunos do curso de Odontologia e 96 alunos do curso de Enfermagem. A seleção da amostragem deu-se de forma aleatória, utilizando como critério de exclusão a recusa em preencher o questionário proposto, bem como buscou-se manter a proporcionalidade da amostra em relação ao número de acadêmicos matriculados em cada curso.

Foi aplicado aos alunos selecionados um questionário composto de 16 questões objetivas, abordando dados biográficos e relacionados à educação sexual, práticas sexuais, aquisição de DST e gravidez não planejada.

Os dados foram apresentados por meio de tabelas, analisados estatisticamente por meio do programa Epi Info versão 3.3 e discutidos a partir da literatura pertinente.

Este trabalho foi previamente aprovado pelo Comitê de Ética em Pesquisa da Universidade Federal do Ceará. Os entrevistados assinaram Termo de Consentimento Livre e Esclarecido, que permitia utilizar os dados na pesquisa e garantia-lhes sigilo e anonimato com relação às suas respostas. Com isto, seguimos as diretrizes e normas de pesquisa envolvendo seres humanos da Resolução No 196/96 do Conselho Nacional de Saúde-Ministério da Saúde.

\section{ANÁLISE E INTERPRETAÇÃO DOS RESULTADOS}

Para se obter uma caracterização geral da amostra, foram investigados sexo, idade, estado civil, crença religiosa, curso superior e semestre que está cursando e a idade de cada um deles quando ingressou no ensino superior. (Tabela 1)

A maioria dos estudantes entrevistados cursava o segundo ano acadêmico (25,7\%), seguidos pelos alunos de primeiro e terceiro ano universitário que alcançaram a mesma porcentagem (25,4\%). Em seguida, verificam-se os alunos do quarto ano $(20,2 \%)$ e os estudantes de quinto ano universitário $(3,3 \%)$.

A amostra desta pesquisa foi composta em sua maioria pelo sexo feminino, que representou $66 \%$ do total, enquanto a participação masculina foi de $34 \%$.

Os estudantes, no momento da entrevista, apresentavam faixa etária predominante de 20 a 22 anos, correspondendo a 56,4\% da amostra, seguida pelos intervalos de idade de 17 a 19 anos (23,0\%), de 23 a 25 anos (17,2\%) e de 26 a 29 anos (3,4\%).

Com relação ao estado civil dos entrevistados, observa-se que sua maioria foi composta por jovens solteiros, correspondendo a $92,1 \%$ do total. Também foram encontradas nesta amostra pessoas casadas $(4,6 \%)$, pessoas unidas consensualmente $(2,6 \%)$ e divorciadas $(0,7 \%)$. Ao se investigar a situação conjugal, pode-se constatar que 0 adiamento do casamento é uma atitude comum aos jovens universitários, porém esse fato é reflexo do comportamento que está se estabelecendo no Brasil.

Em pesquisa realizada pelo Instituto Brasileiro de Geografia e Estatística (IBGE), ao comparar a idade dos

\section{Tabela 1:}

Caracterização do perfil geral dos universitários da FFOE. Fortaleza, 2005.

\begin{tabular}{|c|c|c|}
\hline \multicolumn{3}{|c|}{ Caracterização da amostra } \\
\hline \multirow[b]{2}{*}{ Sexo } & Freqüência & Porcentagem \\
\hline & & \\
\hline Feminino & 200 & $66,0 \%$ \\
\hline Masculino & 103 & $34,0 \%$ \\
\hline Total & 303 & $100,0 \%$ \\
\hline Idade & & \\
\hline 17 a 19 anos & 70 & $23,0 \%$ \\
\hline 20 a 22 anos & 171 & $56,4 \%$ \\
\hline 23 a 25 anos & 52 & $17,2 \%$ \\
\hline 26 a 29 anos & 10 & $3,4 \%$ \\
\hline Total & 303 & $100,0 \%$ \\
\hline Estado civil & & \\
\hline Solteiro & 279 & $92,1 \%$ \\
\hline Casado & 14 & $4,6 \%$ \\
\hline Divorciado & 02 & $0,7 \%$ \\
\hline União consensual & 08 & $2,6 \%$ \\
\hline Total & 303 & $100,0 \%$ \\
\hline Crença religiosa & & \\
\hline Católico & 189 & $62,4 \%$ \\
\hline Evangélico & 38 & $12,5 \%$ \\
\hline Espírita & 16 & $5,3 \%$ \\
\hline Não possui religião & 39 & $12,9 \%$ \\
\hline Outros & 13 & $4,3 \%$ \\
\hline Não respondeu & 08 & $2,6 \%$ \\
\hline Total & 303 & $100,0 \%$ \\
\hline Semestre em andamer & & \\
\hline Primeiro ou segundo & 77 & $25,4 \%$ \\
\hline Terceiro ou quarto & 78 & $25,7 \%$ \\
\hline Quinto ou sexto & 77 & $25,4 \%$ \\
\hline Sétimo ou oitavo & 61 & $20,2 \%$ \\
\hline Nono & 10 & $3,3 \%$ \\
\hline Total & 303 & $100,0 \%$ \\
\hline Idade de ingresso & & \\
\hline na Universidade & & \\
\hline 16 a 18 anos & 162 & $53,5 \%$ \\
\hline 19 a 21 anos & 120 & $39,5 \%$ \\
\hline 22 a 25 anos & 20 & $6,5 \%$ \\
\hline Maior de 26 anos & 01 & $0,5 \%$ \\
\hline Total & 303 & $100,0 \%$ \\
\hline
\end{tabular}

cônjuges que se casaram nos anos de 1991 e 2002, averiguouse que, em 2002, as mulheres tinham, em média, 26,7 anos, e os homens, 30,3 anos; enquanto que, em 1991, tanto as mulheres quanto os homens casavam mais cedo $(23,7$ e 27 anos, respectivamente) ${ }^{12}$. Pessoas com maior número de anos de estudos adiam as relações matrimoniais e ainda preferem famílias menores, fazendo também um maior uso de métodos anticoncepcionais (quando usando o condom, protegem-se não só de uma gravidez indesejada, mas também de possíveis DSTs) ${ }^{9}$.

A maioria dos pesquisados era católica $(62,4 \%)$, seguidos pelas pessoas que não possuíam religião (12,9\%), evangélicos $(12,5 \%)$ e espíritas (5,3\%), e 4,3\% dos estudantes referiram possuir outra crença. Existe influência da religião na sexualidade humana, pois a moral cristã, de um modo geral, associa a 
sexualidade ao pecado, com exceção apenas para o aspecto reprodutivo das relações sexuais ${ }^{13}$. Este aspecto é agravado quando as relações sexuais ocorrem fora do matrimônio, sendo isto 0 acontece com a maioria dos jovens atualmente.

A maioria dos discentes ingressou na universidade dos 16 aos 18 anos (53,5\%), seguidos pelas pessoas que iniciaram seu curso superior dos 19 aos 21 anos (39,5\%), dos 22 aos 25 anos $(6,5 \%)$ e com mais de 26 anos $(0,3 \%)$.

Ao se averiguar a continuidade do tipo de parceria nos relacionamentos atuais dos indivíduos investigados, observaram-se os dados apresentados na Tabela 2:

Tabela 2:

Caracterização da vida sexual atual de universitários da FFOE. Fortaleza, 2005.

Vida Sexual Atual dos Universitários, FFOE, 2005

\begin{tabular}{|c|c|c|c|}
\hline & & 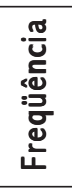 & 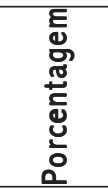 \\
\hline \multicolumn{4}{|l|}{ Parceiro fixo } \\
\hline \multirow[t]{2}{*}{ Sim } & Feminino & 102 & $85,7 \%$ \\
\hline & Masculino & 58 & $63,0 \%$ \\
\hline \multirow[t]{2}{*}{ Não } & Feminino & 17 & $14,3 \%$ \\
\hline & Masculino & 34 & $37,0 \%$ \\
\hline \multirow[t]{2}{*}{ Total } & Feminino & 119 & $100,0 \%$ \\
\hline & Masculino & 92 & $100,0 \%$ \\
\hline \multicolumn{4}{|l|}{$\begin{array}{l}\text { Número de parceiros } \\
\text { nos últimos três meses }\end{array}$} \\
\hline \multirow[t]{2}{*}{$1-3$} & Feminino & 113 & $95,0 \%$ \\
\hline & Masculino & 82 & $89,1 \%$ \\
\hline \multirow[t]{2}{*}{$4-6$} & Feminino & 1 & $0,8 \%$ \\
\hline & Masculino & 5 & $5,4 \%$ \\
\hline \multirow[t]{2}{*}{ Mais de 6} & Feminino & 0 & $0,0 \%$ \\
\hline & Masculino & 3 & $3,3 \%$ \\
\hline \multirow[t]{2}{*}{ Nenhum } & Feminino & 2 & $1,7 \%$ \\
\hline & Masculino & 1 & $1,1 \%$ \\
\hline \multirow[t]{2}{*}{ Não respondeu } & Feminino & 3 & $2,5 \%$ \\
\hline & Masculino & 1 & $1,1 \%$ \\
\hline \multirow[t]{2}{*}{ Total } & Feminino & 119 & $100,0 \%$ \\
\hline & Masculino & 92 & $100,0 \%$ \\
\hline \multicolumn{4}{|l|}{$\begin{array}{l}\text { Frequeência de relações } \\
\text { nos últimos três meses }\end{array}$} \\
\hline \multirow[t]{2}{*}{ Diariamente } & Feminino & 8 & $6,7 \%$ \\
\hline & Masculino & 4 & $4,3 \%$ \\
\hline \multirow[t]{2}{*}{ Semanalmente } & Feminino & 66 & $55,5 \%$ \\
\hline & Masculino & 47 & $51,1 \%$ \\
\hline \multirow[t]{2}{*}{ Mensalmente } & Feminino & 32 & $26,9 \%$ \\
\hline & Masculino & 32 & $34,8 \%$ \\
\hline \multirow[t]{2}{*}{ Outros ${ }^{1}$} & Feminino & 10 & $8,4 \%$ \\
\hline & Masculino & 6 & $6,5 \%$ \\
\hline \multirow[t]{2}{*}{ Nenhum } & Feminino & 1 & $0,8 \%$ \\
\hline & Masculino & 1 & $1,1 \%$ \\
\hline \multirow[t]{2}{*}{ Não respondeu } & Feminino & 2 & $1,7 \%$ \\
\hline & Masculino & 2 & $2,2 \%$ \\
\hline \multirow[t]{2}{*}{ Total } & Feminino & 119 & $100,0 \%$ \\
\hline & Masculino & 92 & $100,0 \%$ \\
\hline
\end{tabular}

Nota 1: Alguns entrevistados especificaram em seus questionários freqüencias que não se enquadravam nas respostas propostas, tais como anualmente.
Dentre outros riscos que suscetibilizam os indivíduos às infecções por DST, vale ressaltar o aumento desses em proporção à quantidade de parceiros sexuais; as vias de sexo adotadas, dentre as quais o sexo oral e anal expõe a uma carga virótica e bacteriana potencialmente maior; o não-uso do preservativo nas relações sexuais ${ }^{14}$.

Das 211 pessoas investigadas que já iniciaram sua vida sexual, $160(75,8 \%)$ relatam possuir parceiro sexual fixo, enquanto $51(24,2 \%)$ não o possuem. A existência de uma relação de confiança entre os parceiros pode ocasionar a displicência com relação ao uso de métodos contraceptivos que previnam a ocorrência de DST.

Questionaram-se os nossos entrevistados sobre o número de parceiros sexuais nos últimos três meses, e foi verificado que a grande maioria, tanto dos homens quanto das mulheres, respondeu que o número variou entre 1 e 3 parceiros $(89,1 \%$ para homens e $95,0 \%$ para mulheres). As mulheres ainda responderam 4 a 6 parceiros $(0,8 \%)$ ou nenhum $(1,7 \%)$. Nenhuma mulher respondeu que possuiu mais de 6 parceiros nos últimos três meses. Com relação aos homens, estes responderam que possuíram de 4 a 6 parceiros $(5,4 \%)$, mais de 6 parceiros $(3,3 \%)$ ou nenhum parceiro $(1,1 \%)$. Assim observado, enfatiza-se a vulnerabilidade dos jovens que mais se expõem em proporção a um maior número de parceiros sexuais e a não-proteção pelo não uso do preservativo ${ }^{15}$.

Quando se indagou sobre a freqüência de relações sexuais dos participantes nos últimos três meses, constatou-se que a maioria, tanto dos homens quanto das mulheres, relatou ter relações semanalmente $(55,5 \%$ para mulheres e $51,1 \%$ para os homens). As mulheres relataram as freqüências: mensalmente $(26,9 \%)$, anualmente $(8,4 \%)$, diariamente $(6,7 \%)$, e $0,8 \%$ não tiveram relações sexuais nos três meses antecedentes à pesquisa. Os homens relataram as seguintes freqüências: mensalmente $(34,8 \%)$, anualmente $(6,5 \%)$, diariamente $(4,3 \%)$, e 1,1\% dos homens não tiveram relação sexual nos últimos três meses.

Durante 0 ato sexual, há uma relevante troca de fluidos sexuais, o que se relaciona diretamente à transmissão de diversos microorganismos, inclusive o HIV, dependendo principalmente da prática sexual realizada. 0 sexo vaginal e 0 anal apresentam um grande risco para ambos os parceiros, quando realizados sem camisinha, já que a troca de fluidos é intensa. Na prática de sexo oral, este risco está presente, porém em menor intensidade. Se houver pequenas lesões, o risco é potencialmente aumentado ${ }^{15}$.

Com base na tabela 3, observa-se que a porcentagem dos entrevistados que mais se expõem às infecções é daqueles que sempre têm relação sexual sem camisinha, penetração oral $(19,9 \%)$, vaginal $(14,7 \%)$ ou anal $(1,4 \%)$; e dos que freqüentemente fazem uso dessas práticas, igualmente sendo elas oral $(32,2 \%)$, vaginal $(20,4 \%)$ ou anal $(3,3 \%)$. Já quanto à freqüência das práticas de menor risco, observa-se que $6,6 \%$ praticam a masturbação e as carícias, ditas como sexo sem penetração.

Os entrevistados que afirmaram sempre fazer o uso de preservativos apresentaram, segundo o tipo de penetração, as 


\section{Tabela 3:}

Caracterização por freqüência das práticas sexuais por uso de preservativo de universitários da FFOE. Fortaleza, 2005.

\begin{tabular}{l|c|c|c|c|c|c}
\hline & Nunca & Raramente & Freqüente & Sempre & Não Respondeu & Total \\
\cline { 2 - 6 } Sexo sem penetração & 32 & 88 & 61 & 14 & 16 & 211 \\
$\%$ & $15,2 \%$ & $41,7 \%$ & $28,9 \%$ & $6,6 \%$ & $7,6 \%$ & $100,0 \%$ \\
Sem preservativo & & & & & & \\
Sexo oral & 44 & 52 & 68 & 42 & 5 & 211 \\
$\%$ & $20,9 \%$ & $24,6 \%$ & $32,2 \%$ & $19,9 \%$ & $2,4 \%$ & $100,0 \%$ \\
Sexo vaginal & 75 & 56 & 43 & 31 & 6 & 211 \\
$\%$ & $35,5 \%$ & $25,5 \%$ & $20,4 \%$ & $14,7 \%$ & $2,8 \%$ & $100,0 \%$ \\
Sexo anal & 150 & 20 & 7 & 3 & 31 & 211 \\
$\%$ & $71,1 \%$ & $9,5 \%$ & $3,3 \%$ & $1,4 \%$ & $14,7 \%$ & $100,0 \%$ \\
Com preservativo & & & & & & \\
Sexo oral & 149 & 34 & 19 & 4 & 5 & 211 \\
$\%$ & $70,6 \%$ & $16,1 \%$ & $9,0 \%$ & $1,9 \%$ & $2,4 \%$ & $100,0 \%$ \\
Sexo vaginal & 17 & 47 & 64 & 78 & 5 & 211 \\
$\%$ & $8,1 \%$ & $22,3 \%$ & $30,3 \%$ & $37,0 \%$ & $2,4 \%$ & $100,0 \%$ \\
Sexo anal & 134 & 32 & 7 & 16 & 22 & 211 \\
$\%$ & $63,5 \%$ & $15,2 \%$ & $3,3 \%$ & $7,6 \%$ & $10,4 \%$ & $100,0 \%$ \\
\hline
\end{tabular}

seguintes freqüências: 37,0\% (vaginal), 7,6\% (anal) e 1,9\% (oral). É importante ressaltar que aqueles que afirmaram fazer uso do preservativo com maior freqüência somente estarão protegidos nas relações com o uso de condom. Os indivíduos que usam condom freqüentemente (30,3\% vaginal, $9,0 \%$ oral e $3,3 \%$ anal) apresentam menor risco que aqueles que raramente utilizam o preservativo (22,3\% vaginal, $15,2 \%$ anal e $16,1 \%$ oral) ou nunca ( $8,1 \%$ vaginal, $63,5 \%$ anal e $70,6 \%$ oral).

De acordo com as freqüências apresentadas, verificou-se que alguns jovens, apesar do maior nível de escolaridade, negligenciam o uso do preservativo durante as práticas sexuais, estando vulneráveis à aquisição de DST e a uma gravidez indesejada.

São inúmeras as vantagens de se usar o preservativo. Dentre elas, destacam-se: a prevenção de DST/AIDS; a nãointerferência no ciclo menstrual; a divisão da responsabilidade da contracepção entre o homem e a mulher; a distribuição gratuita; e a ausência de efeitos colaterais, com exceção de uma possível irritação, que pode ser solucionada com a troca do tipo de condom e com o uso de lubrificante à base de água $^{16}$. Contudo, o indivíduo somente estará protegido nas relações que estiver utilizando o preservativo. Por este motivo, a freqüência do uso do condom torna-se um determinante na prevenção a DST e a gravidez.

Quando indagados se atualmente possuíam ou não parceiro sexual fixo, observou-se que $52,8 \%$ dos participantes o têm, e 47,2\%, não. Das 211 pessoas entrevistadas, 199 (94,3\%) usam algum método contraceptivo, sendo que destes, $153(72,5 \%)$ possuem parceiro fixo e $46(21,8 \%)$ não possuem. Das $12(5,7 \%)$ pessoas que relataram não utilizar método contraceptivo, 7 $(3,3 \%)$ possuem parceiro fixo e $5(2,4 \%)$ não o possuem.
A maioria dos entrevistados demonstrou uso consistente do preservativo, pois $38,9 \%$ das pessoas que iniciaram a vida sexual declararam utilizar preservativo em todas as suas relações sexuais, seguidos por aqueles que usam preservativo com parceiros fixos $(20,9 \%)$. Já aqueles que apresentam uso inconsistente do preservativo são os representantes da amostra que somente o usam com parceiros esporádicos $(10,0 \%)$ e os que nunca o usam (8,5\%), bem como aqueles que nem sempre o utilizam (18,0\%). Não responderam a esta pergunta 3,8\% dos sexualmente ativos. Àqueles que em todas as relações fizeram uso e acondicionamento do preservativo de forma correta, submeteram-se à margem de segurança de $99 \%$ contra a AIDS e, durante 0 ano, de $97 \%$ para gravidez não planejada, com uso correto, e de $86 \%$ se usado sem muitos cuidados ${ }^{17}$.

Dentre as pessoas que tem maior grau de escolaridade, 0 uso de preservativo mostrou-se com maior consistência, porém esse não é o único fator que influencia na adoção da prática sexual com o condom. Sabe-se, ainda, que a idade, tipo de vínculo com o parceiro e o nível de informação quanto aos métodos preventivos e DST/AIDS são outros fatores que interferem nessa prática ${ }^{18}$. Os jovens atualmente possuem alto nível de conhecimento em relação a métodos anticoncepcionais, porém ainda ocorrendo relações sexuais isentas do uso do preservativo ${ }^{19}$. Acredita-se, assim, que o não-uso do preservativo está fortemente relacionado com a esporadicidade e a falta de planejamento das relações sexuais, dentre outros fatores.

$\mathrm{Na}$ tabela 4, dentre os entrevistados que utilizam métodos contraceptivos, a camisinha é o método mais aceito, sendo usado por $148(74,4 \%)$ pessoas, seguido pelos anticoncepcionais hormonais, que são usados por $92(46,2 \%)$ 
pessoas; coito interrompido, que é usado por 17 (8,5\%) pessoas; tabelinha, com 12 (6,0\%) usuários; e a camisinha feminina, que foi o método contraceptivo menos usado, apenas com 1 usuário (0,5\%). Algumas pessoas relataram utilizar mais de um método contraceptivo.

Tabela 4:

Classificação por freqüência do uso de método contraceptivo por parceria sexual da FFOE. Fortaleza, 2005.

\begin{tabular}{l|c|c|c}
\hline \multirow{2}{*}{\begin{tabular}{l|c} 
Usa método \\
contraceptivo
\end{tabular}} & \multicolumn{3}{|c}{ Parceiro sexual fixo } \\
\cline { 2 - 4 } Sim & Sim & Não & Total \\
Não & 153 & 46 & 199 \\
Total & 160 & 51 & 211 \\
& & & \\
Qual o método & & & \\
contraceptivo utilizado & & & \\
Camisinha & 105 & 43 & 148 \\
Anticoncepcionais hormonais & 81 & 11 & 92 \\
Coito interrompido & 14 & 3 & 17 \\
Tabelinha & 12 & 0 & 12 \\
Camisinha feminina & 1 & 0 & 1 \\
Outros métodos & 2 & 0 & 2 \\
\hline
\end{tabular}

Entre as pessoas que não possuem parceiro sexual fixo e que utilizam algum método contraceptivo, o método mais aceito é a camisinha masculina com 93,5\% de aceitação. Entre estes universitários também são aceitos os anticoncepcionais hormonais $(23,9 \%)$ e o coito interrompido $(6,5 \%)$. Os outros métodos não foram citados pelas pessoas que não possuem parceiro fixo. É importante ressaltar que métodos como coito interrompido e tabelinha são considerados de baixa eficácia quando utilizados isoladamente.

Tabela 5 :

Classificação por freqüência de ocorrência de DST da FFOE. Fortaleza, 2005

\begin{tabular}{l|c|c}
\hline & Freqüência & Porcentagem \\
\hline Contraiu DST & & \\
Não & 174 & $82,5 \%$ \\
Não respondeu & 1 & $0,5 \%$ \\
Não sabe & 20 & $9,5 \%$ \\
Sim & 16 & $7,6 \%$ \\
Total & 211 & $100,0 \%$ \\
& & \\
Contraiu qual DST & & \\
Candidíase & 9 & $52,9 \%$ \\
Gonorréia & 1 & $5,9 \%$ \\
Herpes Genital & 1 & $5,9 \%$ \\
Outros & 6 & $35,3 \%$ \\
Total & 17 & $100,0 \%$ \\
\hline
\end{tabular}

As doenças sexualmente transmissíveis (DST) constituemse um crescente problema de saúde nas últimas décadas. Embora os dados relacionados às DST não revelem de forma fidedigna sua real magnitude, e não permitam a realização de inferências sobre sua ocorrência no Brasil, a conjugação desses dados com outros obtidos no âmbito internacional permite a realização de estimativas que confirmam sua elevada prevalência. A Organização Mundial de Saúde estima que ocorram cerca de 340 milhões de casos de DST por ano, no mundo ${ }^{20}$.

$\mathrm{Na}$ tabela 4, quando se questionou sobre a ocorrência de doenças sexualmente transmissíveis nos participantes, constatou-se que a maioria que iniciou vida sexual referiu nunca ter contraído uma delas (82,5\%), seguida daquelas pessoas que não sabem se já contraíram uma DST $(9,5 \%)$ e das pessoas que já foram contaminadas durante 0 ato sexual $(7,6 \%)$.

Entre os jovens que já contraíram uma DST, houve 9 $(52,9 \%)$ casos de candidíase, $1(5,9 \%)$ caso de gonorréia, $1(5,9 \%)$ caso de herpes genital, $6(35,3 \%)$ de outras DST e nenhum caso de AIDS, sífilis, cancro mole ou cancro duro. Ressalta-se que um mesmo jovem referiu ter contraído duas diferentes DST.

As DST acarretam não somente afecções físicas, que podem levar às disfunções sexuais, esterilidade, danos fetais, abortamentos, alguns tipos de câncer e até à morte, mas também geram impactos psicossociais em seus portadores. Além disso, os custos gerados para o tratamento da crescente demanda acarretam um importante impacto no sistema de saúde, produzindo gastos de milhões todos os anos, decorrentes de internações e procedimentos para o tratamento de suas complicações. E, embora a prevenção e o controle das DST estejam sendo priorizados, essas ainda se constituem um dos mais comuns problemas de saúde ${ }^{21}$.

Outro fator também passível de prevenção, aqui investigado por sua considerável importância como fator modificador de papéis sociais, especialmente quando se trata de pessoas na faixa etária aqui especificada, foi a freqüência de gravidezes ocorridas nesse grupo de universitários. Através desse inquérito obtiveram-se os dados que seguem, na tabela 6 .

Nesta pesquisa foram encontradas 18 gestações. Duas mulheres relataram ter tido duas gestações, nove mulheres tiveram somente uma gestação e os cinco homens que relataram ter engravidado suas parceiras o fizeram somente uma vez. Essas gestações resultaram, na maioria das vezes, em crianças nascidas vivas $(66,7 \%)$, e as outras em aborto provocado $(22,2 \%)$ e aborto espontâneo $(11,1 \%)$.

Constatou-se que das 16 pessoas que engravidaram, 3 $(18,75 \%)$ eram casadas, $2(12,5 \%)$ eram divorciadas, 8 $(50,0 \%)$ eram solteiras e $3(18,75 \%)$ viviam em situação de uniões consensuais.

Verificou-se que a maioria dos casos de gravidez aconteceu entre universitários solteiros $(50,0 \%)$. 0 namoro pode ser a principal maneira como universitários mantêm uma relação afetivo-sexual, favorecendo, juntamente com a esporadicidade e o não- planejamento do ato sexual, o fato de a maioria das gravidezes ter ocorrido fora de uniões reconhecidamente estáveis. 0 namoro é o principal cenário das relações sexuais 
Tabela 6:

Caracterização por freqüência das gestações dos universitários da FFOE. Fortaleza, 2005.

\begin{tabular}{|c|c|c|}
\hline & Freqüência & Porcentagem \\
\hline $\begin{array}{l}\text { Ocorreu gravidez } \\
\text { Sim } \\
\text { Não }\end{array}$ & $\begin{array}{c}16 \\
287\end{array}$ & $\begin{array}{c}5,29 \% \\
94,71 \%\end{array}$ \\
\hline $\begin{array}{l}\text { Sexo } \\
\text { Feminino } \\
\text { Masculino } \\
\text { Total }\end{array}$ & $\begin{array}{c}5 \\
11 \\
16\end{array}$ & $\begin{array}{c}31,2 \% \\
68,8 \% \\
100,00 \%\end{array}$ \\
\hline $\begin{array}{l}\text { Estado civil } \\
\text { Casado } \\
\text { Solteiro } \\
\text { Divorciado } \\
\text { União consensual } \\
\text { Total }\end{array}$ & $\begin{array}{c}3 \\
8 \\
2 \\
3 \\
16\end{array}$ & $\begin{array}{c}18,75 \% \\
50,00 \% \\
12,50 \% \\
18,75 \% \\
100,00 \%\end{array}$ \\
\hline $\begin{array}{l}\text { Usa método contraceptivo } \\
\text { Camisinha } \\
\text { Anticoncepcional hormonal } \\
\text { Coito interrompido } \\
\text { Tabelinha } \\
\text { Camisinha feminina } \\
\text { Outros }\end{array}$ & $\begin{array}{c}4 \\
13 \\
4 \\
1 \\
0 \\
1\end{array}$ & $\begin{array}{c}25,0 \% \\
81,25 \% \\
25,0 \% \\
6,25 \% \\
0,0 \% \\
6,25 \%\end{array}$ \\
\hline $\begin{array}{l}\text { Contraiu DST } \\
\text { Candidíase } \\
\text { Herpes genital } \\
\text { Total }\end{array}$ & $\begin{array}{l}3 \\
1 \\
4\end{array}$ & $\begin{array}{c}18,75 \% \\
6,25 \% \\
100,0 \%\end{array}$ \\
\hline $\begin{array}{l}\text { Resultado da gravidez } \\
\text { Aborto provocado } \\
\text { Aborto espontâneo } \\
\text { Nascido vivo } \\
\text { Nascido morto } \\
\text { Total }\end{array}$ & $\begin{array}{c}4 \\
2 \\
12 \\
0 \\
18\end{array}$ & $\begin{array}{c}22,2 \% \\
11,1 \% \\
66,7 \% \\
0,0 \% \\
100,0 \%\end{array}$ \\
\hline
\end{tabular}

e é uma variável importante para a compreensão do comportamento sexual e reprodutivo ${ }^{9}$.

Após a experiência de pelo menos uma gestação, poucos universitários $(25,0 \%)$ utilizam condom, contrastando com um alto índice do uso de anticoncepcionais (81,25\%). A utilização do anticoncepcional hormonal gera certa acomodação com relação ao uso do condom, fazendo com que $25,0 \%$ dos universitários que afirmaram gravidez nesta pesquisa já tenham contraído alguma DST. Apesar de o conhecimento ser importante, o uso de contraceptivos, tanto de barreira como hormonais, não estão sempre associados aos conhecimentos ${ }^{22}$, mesmo com maior nível de instrução.
A maioria dos entrevistados obteve informações acerca de sexualidade entre amigos, ou seja, uma fonte que é considerada infiel, já que as pessoas podem transmitir informações errôneas acerca do tema, inclusive pela falta de experiência. Os jovens recebem informações limitadas e inadequadas, proveniente de amigos, de pessoas pouco preparadas para esta função $0^{23}$.

\section{CONCLUSÕES}

0 tipo de prática sexual realizada pode determinar uma maior ou menor exposição aos riscos. Os estudantes entrevistados parecem ser conscientes disto, pois, no tipo de relação sexual comprovadamente mais exposto a riscos para a saúde, eles utilizavam preservativo.

Os resultados encontrados mostram que, mesmo se tratando de pessoas com um maior nível de escolaridade, não há uma grande diferença quanto às porcentagens daqueles que tomam os devidos cuidados em relação àqueles que negligenciam a segurança, variando de acordo com a prática sexual adotada.

De acordo com a pesquisa, os universitários utilizam com maior freqüência o condom quando realizam sexo vaginal e menos quando do sexo oral. Destaca-se o baixo número de universitários que usam o condom em todas as relações sexuais. Os demais usam apenas com determinados tipos de parceiros (fixo ou esporádico) ou até mesmo nunca usam. Isto nos mostra que estes universitários, conscientemente ou não, podem ter determinados critérios para o uso do preservativo, estando sujeitos aos riscos inerentes a uma relação sexual desprotegida.

Verificou-se, ainda, o alto índice do uso de métodos contraceptivos e a baixa ocorrência de gravidez, de aborto e DST. 0 método anticoncepcional mais relatado foi a camisinha, tanto por aqueles que não têm parceiro fixo como por aqueles que o possuem. Entendemos que isto se deve à dupla função do condom: prevenção de DST e de gravidez indesejada.

0 relacionamento com parceiro fixo foi o tipo mais citado pelos universitários, o que significa um menor risco à aquisição de DST, pois quanto menor o número de parceiros, menor o risco de adquirir uma DST.

Esse estudo revelou que, mesmo lidando com pessoas de um alto nível intelectual (universitários), ainda se faz necessária a implantação de políticas educacionais no âmbito da sexualidade, visando à orientação de jovens quanto às práticas sexuais, a fim de reduzir a incidência de DST/AIDS e gravidez indesejada nessa população; tornar os jovens mais responsáveis e mais atentos quanto aos cuidados com a saúde sexual deles e de seus parceiros e, imprescindivelmente, tornálos multiplicadores da saúde, com a dispersão de informações confiáveis e, assim, diminuir a exposição dos jovens a riscos que prejudiquem a saúde. 
17. Bezerra VC. Sexualidade, uso do preservativo e direito reprodutivo. Rev Saber Viver 2004 jan; ed esp profissionais de saúde: 24-26.

1. Freitas F, Menke CH, Rivore W, Passos EP. Rotinas em ginecologia. $4^{\mathrm{a} e d .}$. Porto Alegre (RS): Artmed; 2003.

2. Berger I, Hutz CS. 0 perfil do educador gaúcho em relação à sexualidade. Rev Bras Sex Hum 1999 jan/ jun; 10 (1): 89-118.

3. Ribeiro PRC, Souza NGS, Souza DO. Sexualidade na sala de aula: pedagogias escolares de professoras das séries iniciais do Ensino Fundamental. Rev Estud Fem 2004; 12 (1) .

4. Gir E, Nogueira MS, Pelá NTR. Sexualidade humana na formação do enfermeiro. Rev Latino-Am Enfermagem, Ribeirão Preto, 2000 abr; 8 (2): 33-40.

5. Martins PCR, Soldatelli MM. Sexo e poder: uma reflexão histórica. Rev Bras Sex Hum 1998 jan/ jun; 9 (1): 33.

6. Loyola MA. Sexualidade e medicina: a revolução do século XX. Cad Saúde Pública 2003 jul/ago; 19 (4): 875-84.

7. Pirotta KCM, Schor N. Intenções reprodutivas e práticas de regulação da fecundidade entre universitários. Rev Saúde Publica 2004 ago; 38(4): 495-502.

8. Fonseca MG, Bastos FI, Derrico M, Andrade CLV, Travassos C, Szwarcwald CL. AIDS e grau de escolaridade no Brasil: evolução temporal de 1986 a 1996. Cad Saúde Pública 2000; 16 (1):77-87.

9. Aquino PS, Eduardo KGT, Barbosa RCM, Pinheiro AKB. Reações da adolescente frente à gravidez. Esc Anna Nery Rev Enferm 2005 ago; 9 (2): 214-20.

10. Ministério da Saúde (BR). Coordenação Nacional de DST e AIDS. Pesquisa de conhecimento, atitudes e práticas na população brasileira de 15 a 54 anos, 2004. Bol Epidemiol AIDS, 2004; [on line] 18 (1): 18-24 [citado 13 out 2005] Disponível em: <http://www.aids.gov.br/ final/dados/BOLETIM2.pdf.>

11. Wood GL, Habeer. Pesquisa em enfermagem: métodos, avaliação crítica e utilização. $4^{\mathrm{a}}$ ed. Rio de Janeiro (RJ): Guanabara Koogan; 2001.

12. Instituto Brasileiro de Geografia e Estatística (IBGE). Síntese de indicadores sociais: [on-line] [citado 05 out 2005]. Disponível em: <http://www.ibge.gov.br/home/presidencia/noticias/ 13042004sintese2003html.shtm.>

13. Ministério da Saúde (BR). Secretaria de Políticas de Saúde. Coordenação Nacional de DST e Aids. Guia de prevenção das DST/Aids e cidadania para homossexuais. Brasília (DF); 2002.

14. Smeltzer SC. Brunner\& Suddarth: Tratado de Enfermagem MédicoCirúrgica 9ªed. Rio de Janeiro (RJ): Guanabara Koogan; 2002.

15. Ministério da Saúde (BR). Secretaria da Saúde. Coletânea de textos para subsídio da capacitação de profissionais facilitadores da JESS e JECSS. Fortaleza (CE); 1998.

16. Silva CV, Brêtas JRS, Ferrreira D, Correa DS, Cintra CC. Uso da camisinha por adolescentes e jovens: avaliação da seqüência dos procedimentos. Acta Paul Enferm 2004 out./dez; 17 (4): 392-99
18. Paiva V, Venturi G, França Junior I, Lopes F. Uso de preservativos. Pesquisa Nacional MS /lbope 2003. [on line] [citado 27 nov 2005]. Disponível em: <http// www.aids.gov.br>

19. Pirotta KCM, Schor N. Intenções reprodutivas e práticas de regulação da fecundidade entre universitários. Rev Saúde Publica 2004 ago; 38(4):495-502.

20. Organização Mundial de Saúde-OMS. Infecciones de transmisión y otras infecciones del tracto reproductivo: una guía para la práctica basica. [on line] [citado 25 jan 2006]. Disponível em: http://www.who.int/ reproductivehealth/publications/es/stis_gep/ text_es.pdf

21. Loudermilk DL, Perry SE, Bobak IM. 0 cuidado em enfermagem materna. $5^{a}$ ed. São Paulo (SP): Artmed; 1999.

22. Bello MV, Silva JLP. Conhecimento, atitude e prática sobre métodos anticoncepcionais entre adolescentes gestantes. Rev Saúde Pública 2004 ago; 38 (4): 479-87

23. Gomes WA, Costa COM, Sobrinho CLN, Santos CAST, Bacelar EB. Nível de informação sobre a adolescência, puberdade e sexualidade entre adolescentes. J Pediatr 2002; 78 (4):301-08

\section{Sobre os Autores}

\section{José Stênio Pinto Falcão Júnior}

Acadêmico do curso de Enfermagem da Universidade Federal do Ceará. Bolsistas do Programa Especial de Treinamento-PET

\section{Emeline Moura Lopes}

Acadêmica do curso de Enfermagem da Universidade Federal do Ceará. Bolsistas do Programa Especial de Treinamento-PET

\section{Lydia Vieira de Freitas}

Acadêmica do curso de Enfermagem da Universidade Federal do Ceará. Bolsistas do Programa Especial de Treinamento-PET

\section{Samia Thábida de Oliveira Rabelo}

Acadêmica do curso de Enfermagem da Universidade Federal do Ceará. Bolsistas do Programa Especial de Treinamento-PET

\section{Ana Karina Bezerra Pinheiro}

Enfermeira; Doutora em Enfermagem; Docente do Departamento de Enfermagem - FFOE/UFC; Co-tutora do PET-Enfermagem/UFC

\section{Lorena Barbosa Ximenes}

Enfermeira; Doutora em Enfermagem; Docente do Departamento de Enfermagem - FFOE/UFC; Tutora do PET-Enfermagem/UFC 